\title{
The Role of User Behaviour in Improving Cyber Security Management
}

\author{
Ahmed A. Moustafa ${ }^{1,2,3 *}$, Abubakar Bello ${ }^{4}$ and Alana Maurushat ${ }^{4}$ \\ 'School of Psychology, Western Sydney University, Sydney, NSW, Australia, ${ }^{2}$ The Marcs Institute for Brain, Behaviour and \\ Development, Western Sydney University, Sydney, NSW, Australia, ${ }^{3}$ Department of Human Anatomy and Physiology, Faculty \\ of Health Sciences, University of Johannesburg, Johannesburg, South Africa, ${ }^{4}$ School of Social Sciences, Western Sydney \\ University, Sydney, NSW, Australia
}

Information security has for long time been a field of study in computer science, software engineering, and information communications technology. The term 'information security' has recently been replaced with the more generic term cybersecurity. The goal of this paper is to show that, in addition to computer science studies, behavioural sciences focused on user behaviour can provide key techniques to help increase cyber security and mitigate the impact of attackers' social engineering and cognitive hacking methods (i.e., spreading false information). Accordingly, in this paper, we identify current research on psychological traits and individual differences among computer system

OPEN ACCESS

Edited by:

Richard Keith Wortley, University College London, United Kingdom

Reviewed by:

Karima Boudaoud,

Université Côte d'Azur, France

Palvi Aggarwal,

Carnegie Mellon University,

United States

*Correspondence:

Ahmed A. Moustafa

a.moustafa@westernsydney.edu.au

Specialty section:

This article was submitted to Cognition,

a section of the journal

Frontiers in Psychology

Received: 11 May 2020 Accepted: 03 May 2021

Published: 18 June 2021

Citation:

Moustafa AA, Bello A and Maurushat $A$ (2021) The Role of User Behaviour in Improving Cyber Security

Management.

Front. Psychol. 12:561011. doi: 10.3389/fpsyg.2021.561011 users that explain vulnerabilities to cyber security attacks and crimes. Our review shows that computer system users possess different cognitive capabilities which determine their ability to counter information security threats. We identify gaps in the existing research and provide possible psychological methods to help computer system users comply with security policies and thus increase network and information security.

Keywords: cyber security, social engineering, information security, phishing, cognitive hacking

\section{INTRODUCTION}

According to National Initiative for Cybersecurity Careers and Studies, cybersecurity is defined as 'the activity or process, ability, or capability or state whereby information and communications systems and the information contained therein are protected from and/or defended against damage, unauthorised use or modification, or exploitation.' Cyber and network systems involve at least four components: computer system users, security system analysts, cyber attackers, and computer systems. Cyber attackers often attempt to obtain, modify, or keep unauthorised information (Landwehr, 1981; Thompson, 2004).

Most of the research on cybersecurity has focused on improving computer network systems (Nobles, 2018), as many believe that information technology advances and software development is the main way to increase information security (Sadkhan, 2019; Benson and Mcalaney, 2020). Fewer studies have been conducted on enhancing cognitive capabilities and situational awareness of system analysts (D'Amico et al., 2005; Barford, 2010; Dutt et al., 2013; Knott et al., 2013; Tyworth et al., 2013; Mancuso et al., 2014; Gutzwiller et al., 2015; Aggarwal et al., 2018; Veksler et al., 2018).

However, cyber attackers can also manipulate the minds of computer system users, rather than a computer system itself, by, for example, using social engineering (e.g., tricking of computer system users to gain information, such as passwords) and cognitive hacking (e.g., spreading of misinformation) to break into a network or computer system (Cybenko et al., 2002; Thompson, 2004; McAlaney et al., 2015; King et al., 2018; Fraunholz et al., 2019). According to 
Bowen et al. (2014), social engineering attacks account for $28 \%$ of total cyber security attacks and $24 \%$ of these attacks occurred due to phishing. According to CyberEdge Reports, more than $70 \%$ of social engineering attacks have been successful in the last few years. In the 2018 and 2019 reports by Telstra, human errors are the greatest threat in cybersecurity. The reports claim that phishing (and spear-phishing) attacks were the most common attacks and they utilised partial social engineering and fraud to scam victims into installing malware or illegitimate websites to acquire their credentials. In these types of attacks, victims are often sent emails or text messages that appear, for example, to be for a software upgrade, legitimate correspondence from a third party supplier, information on a current storm or crisis, or notifications from a bank or a social networking site. In addition to falling victim to phishing attacks, computer system users also conduct other cyber security errors, such as sharing passwords with friends and family and also not installing software updates.

It is important to note that there are individual differences among computer system users in terms of complying with security behaviours. Several studies found that individual differences in procrastination, impulsivity, future thinking, and risk taking behaviours can explain differences in complying with security policies. Importantly, given the existing human errors that can impact network security, we will discuss the use of psychological methods to improve compliance with security policies. Such psychological methods include using novel polymorphic security warnings, rewarding and penalizing good and bad cyber behaviour, and increasing thinking about future consequence of actions.

This paper is structured as follows. First, we discuss studies and measures related to complying with security policies. Second, we discuss kinds of cyber security errors done by many computer system users, including falling victim to phishing, sharing passwords, and not installing software updates and. Third, we discuss individual differences underlying cyber security behaviours in computer system users, including procrastination, impulsivity, future thinking, and risk taking behaviours. We conclude by suggesting psychological methods that could be used to move user behaviour toward secure practices.

\section{COMPLYING WITH SECURITY POLICIES}

Complying with security policies is one key behaviour to protect computer and network systems. There have been few studies on the psychology of compliance with security policies (Chan et al., 2005; Lee and Kozar, 2005; Hazari et al., 2009; Anderson and Agarwal, 2010; Maurushat, 2010; Guo et al., 2011). A lack of complying with security policies can significantly undermine information security (Greenwald et al., 2004; Mishra and Dhillon, 2006; West, 2008). For example, several studies have shown that computer system users often ignore security warnings (Schechter et al., 2007; Akhawe and Felt, 2013; Bravo-Lillo et al., 2013; Brase et al., 2017).

To measure such humans' security behaviours, Egelman and Peer (2015) developed the Security Behaviour Intentions scale.
The scale measures attitudes toward choosing passwords, device security, regularly updating software, and general awareness about security attacks. The scale has 16 questions, such as (a) I use a password/passcode to unlock my laptop or tablet, (b) When I'm prompted about a software update, I install it right away, (c) I manually lock my computer screen when I step away from it, and (d) If I discover a security problem, I continue what I was doing because I assume someone else will fix it. The scale itself represents very basic aspects of security protection and mitigation techniques. As we discuss below, several studies have used this scale to measure types of security errors done by computer system users.

Non-compliance with a security policy can go beyond mere ignoring warnings, choosing poor passwords or failing to adopt recommended security measures. In a recent study, Maasberg et al. (2020) found that the dark triad traits (machiavellianism, narcissism and psychopathy, machiavellianism, narcissism and psychopathy, Paulhus and Williams, 2002) correlate with malicious behaviour intentions such as insider threats. Harrison et al. (2018) recently reported that the Dark triad can explain unethical behaviour such as committing cyber fraud. The concept of Dark Triad and Big Five Methods will be explored and critiqued further in the following section.

\section{HUMAN CYBER SECURITY ERRORS}

In this section, we describe the kinds of cyber security errors conducted by many computer system users. Several reports have shown that humans are considered the greatest vulnerability to security (Schneier, 2004; Furnell and Clarke, 2012), which has been also confirmed by recent reports. One report estimated that $95 \%$ of cyber and network attacks are due to human errors (Nobles, 2018). In our context, humans are either computer system users or security analysts (King et al., 2018; Andrade and Yoo, 2019), though most research on this area focuses on errors done by computer system users. According to Ifinedo (2014), company employees are the weakest link in ensuring system security (for discussion and analysis, also see Sasse et al., 2004; Vroom and von Solms, 2004; Stanton et al., 2005; Guo et al., 2011).

Some human errors related to cyber and network security include, but not limited to, sharing passwords, oversharing information on social media, accessing suspicious websites, using unauthorised external media, indiscriminate clicking on links, reusing the same passwords in multiple places, opening an attachment from an untrusted source, sending sensitive information via mobile networks, not physically securing personal electronic devices, and not updating software (Boyce et al., 2011; Calic et al., 2016). Along these lines, one main issue underlying information and cyber security is the dilemma of increasing availability and ease to access a network or data but, at the same time, maintain security (Veksler et al., 2018). To increase security, organisations often require computer system users to have complex passwords, which makes usability quite difficult. Computer system users, however, tend to take the path of least resistance, such as using a weak password and 
using the same password for several websites. Below, we discuss prior studies on three kinds of human security errors: falling victim to phishing, sharing passwords with others, and installing software updates.

Falling victim to phishing: Some phishing studies have used a laboratory-based phishing experiment (Jakobsson and Ratkiewicz, 2006; Jagatic et al., 2007). The use of laboratorybased phishing experiment has been shown in a recent study to relate to real-life phishing (Hakim et al., 2020). One study found that over $30 \%$ of government employees click on a suspicious link in this phishing email, and many of these have provided their passwords (Baillon et al., 2019). In another study using a similar phishing experiment, around $60 \%$ of university students clicked on suspicious link in a phishing email (Diaz et al., 2018). Accordingly, several studies suggest that human factors, behavioural studies, and psychological research must be considered in cyber and network security studies (Hamill and Deckro, 2005; Jones and Colwill, 2008). In another study, Bowen et al. (2014) studied how Columbia University students and academic staff respond to phishing emails, and found that it took people around 4 rounds to discover they are receiving phishing emails.

One recent study also found that a successful phishing attack is related to the Dark Triad traits of the computer users, including machiavellianism, narcissism, and psychopathy (Curtis et al., 2018). In this study, it was found that high scores in narcissism is related to a higher tendency to fall victim to phishing attempts. Along these lines, it was found that neuroticism is related to falling victim to phishing attacks (Halevi et al., 2013). In another study by Gonzalez and colleagues (Rajivan and Gonzalez, 2018), it was found that the use of some cyberattack strategies, such as sending excessive amount of notification and expressing shared interest, were more related to successful phishing.

One study found that even warning people about phishing does not change their response to phishing emails (Mohebzada et al., 2012). Using the Human Aspects of Information Security Questionnaire (HAIS-Q) (Calic et al., 2016; Parsons et al., 2017), it was found that individuals who scored high on the HAIS-Q performed better on a laboratory-based phishing experiment, in which a randomly selected sample of participants (from a firm, university, school, or so) are unknowingly sent a phishing email that urges them to share their password. Herath and Rao (2009) found that computer system users generally underestimate the probability of security breaches and cybercrimes happening to them.

Sharing passwords: Sharing passwords with friends and family, and even strangers is a prevalent example of human cyber security errors. According to Whitty et al. (2015), older adults who score high on perseverance and self-monitoring are more likely to share passwords. Sharing passwords may lead to financial exploitation of older adults, which is among the most common forms of abuse (Bailey et al., 2015). This is the case as many older adults are very trusting of others and strangers, especially on the internet. Like older adults, younger adults also share passwords, especially ones for streaming systems. Younger users (who had grown up with computers) perceived security as an obstacle they had to work around (Smith, 2003). Sharing passwords is generally problematic as most people often use the same passwords for several websites, and thus by sharing a password, others can access their other secure information. One problem with using the same password in many systems is that cybercriminals, once find these passwords in one system, can use these passwords in many other websites.

Installing software updates: One common error underlying cybersecurity behaviours is a delay in or even not at all installing software updates (Rajivan et al., 2020). Using an experimental behavioural decision making study, Rajivan et al. (2020) found that risk-taking behaviours can partly explain some individuals behaviours regarding installing software updates, such that individuals who are more risk taking tend to delay the installation of software updates. Unlike sharing passwords and phishing, the area of installing software updates has not received much attention in the field.

\section{INDIVIDUAL DIFFERENCES UNDERLYING CYBER SECURITY BEHAVIOURS}

Individual differences in personality, cognitive and behavioural traits are related to cyber security behaviours. Dawson and Thomson (2018) argue that individual differences in cognitive abilities and personality traits can play a key role in success to secure computer and information systems. Below, we discuss some of these psychological traits.

Procrastination: Complying with security policies is possibly related to cognitive processes, such as working hard to achieve certain goals. One scale, known as "the need for cognition" scale measures working hard, enjoying and participating in activities that require efforts and thinking (Lin et al., 2016). Along these lines, Egelman and Peer (2015) found that performance in the Security Behaviour Intentions Scale is related to the Need for Cognition (NFC), which refers to inclination to exerting cognitive efforts (Cacioppo et al., 1984). Interestingly, a new study has developed a scale to measure procrastination in children and adolescents, which is suitable for the increasing number of young internet users (Keller et al., 2019). Along these lines, Shropshire et al. (2006) reported a link between the intent to comply with information security protocols and conscientiousness (i.e., doing work thoroughly and accurately) (McBride et al., 2012). Further, using the General Decision-Making Style (GDMS) scale (Scott and Bruce, 1995), Egelman and Peer (2015) found that performance in the Security Behaviour Intentions Scale is related to procrastination, such that, individuals who procrastinate were less likely to follow security policies. This is plausible as procrastination is negatively correlated with active participation in activities (Sarmany-Schuller, 1999).

Impulsivity: Complying with security policies may be also related to individual differences in impulsive behaviours. Egelman and Peer (2015) found that performance in the Security Behaviour Intentions Scale is related to Barratt Impulsiveness Scale scores (Patton et al., 1995). Another study found that internet addiction and impulsivity predicts risky cyber behaviours (Hadlington, 2017). Along these lines, Hu et al. (2015) 
found that individual differences in self and cognitive control (a key feature of impulsive behaviours) is related to violation of information security policies. Wiederhold (2014) also found that people fall victim to cybersecurity attacks in the pursuit of immediate gratification. One key feature related to impulsivity is thinking about future consequences of one's actions (e.g., saving money now to buy a house in the future vs. spending all money now to enjoy life).

Future thinking: Importantly, complying with security policies may also be related to thinking about the future as well as impact of present actions on future consequences (A. A. Moustafa et al., 2018a; Moustafa et al., 2018b). In other words, individuals who think more about the future may abide by security rules to make sure their computer system is safe in the future. Along these lines, Egelman and Peer (2015) found that performance in the Security Behaviour Intentions Scale is related to Consideration for Future Consequences (CFC) (Joireman et al., 2012). This scale includes items that are very relevant to cyber security behaviours, such as 'I consider how things might be in the future, and try to influence those things with my day to day behaviour,' 'I think it is important to take warnings about negative outcomes seriously even if the negative outcome will not occur for many years', and 'When I make a decision, and I think about how it might affect me in the future'.

Risk taking behaviours: Another personality trait related to cyber security is risk taking behaviours. Some studies have found that computer system users who are high in risk taking may be more likely to fall victims to cybercrimes (Henshel et al., 2015; King et al., 2018). Risk is defined as engaging in a behaviour with an uncertain outcome, usually for the benefit of gaining more (Saleme et al., 2018). For example, robbing a bank is risky, as one may get caught. A lack of complying with security policies is risky as the benefit is not doing any additional work, such as software update (which is rewarding), but the risk is falling victim to cybercrimes and phishing. Another example is finding out that there has been a data breach where your personal information such as your username and password has been compromised, but then not doing anything to change your password. The dilemma computer system users face is doing additional work to secure their network or computer systems (too much work but more safe) or not (less work but less safe). Importantly, Egelman and Peer (2015) found that performance in the Security Behaviour Intentions Scale is related to performance in the DomainSpecific Risk-Taking Scale, which has items on general risk taking behaviours in everyday life (Blais and Weber, 2006; Saleme et al., 2018; Saleme and Moustafa, 2020). In several studies, by using the Risky Cybersecurity Behaviours Scale, Security Behaviours Intentions Scale (SeBIS), and Attitudes toward cybersecurity and cybercrime in business (ATC-IB), Hadlington and colleagues (Hadlington, 2017; Hadlington and Murphy, 2018) found that heavy media multitasking is associated with risky cybersecurity behaviours and increased cognitive errors.

Optimism bias is related to risk-based decision making. There have few psychology studies on optimism bias in humans (West, 2008; Sharot, 2011; Moutsiana et al., 2013; Garrett and Sharot, 2017). Generally, people assume that the best will happen to them, and they do not think they are at risk (West, 2008), that is, humans tend to be more optimistic and discount the likelihood of negative events happening to them. For example, people generally do not assume they will have cancer disease, and often discount the likelihood of it happening. This is relevant to research on the psychology of cyber and network security as computer system users may tend to discount the impact of cyber-attacks or crimes happening to them. For example, one study found that people fall victim to cybersecurity attacks due to optimism bias (Wiederhold, 2014). Importantly, future work should investigate individual differences in optimism bias and its relationship to risky cybersecurity behaviours.

Other areas of study that have examined individual differences in cybersecurity are considered under the framework of the Dark Triad and the Big Five Model. The majority of these studies are in the field of cyber bullying which falls outside of the scope of this paper, but other studies have been incorporated into sections of this paper (West, 2008; Goodboy and Martin, 2015; Jacobs et al., 2015; Alonso and Romero, 2017; Rodriguez-Enriquez et al., 2019; Curtis et al., 2021). The Big Five Scale has also been used in cybersecurity and psychology studies. The Big Five Scales refers to Agreeableness, Neuroticism, Openness, Conscientious and Extraversion. We have found, however, that the literature refers to only Neuroticism, Openness and Extraversion. Instead of examining the individual differences of the limited approach of the dark triad and the Big Five Scales we have instead pulled out the multi-dimensional aspects involved with the triad. For example, impulsivity is one component that expands across the different indexes of measurement. The other factors are grouped in Table 1.

In sum, in this section, we reviewed prior studies showing that personality traits and individual differences in procrastination, impulsivity, and risk-taking behaviours, are related to cyber security behaviours.

\section{IMPROVING SECURITY BEHAVIOURS USING PSYCHOLOGICAL METHODS}

As discussed above, cyber attackers often use social engineering and cognitive hacking methods to break into a network or computer systems (Cybenko et al., 2002; Thompson, 2004; McAlaney et al., 2015; King et al., 2018; Fraunholz et al., 2019). Some computer system users may have some personality traits that make them likely to fall victims to phishing. Accordingly, it is important to equip vulnerable computer system users (i.e., those who may not comply with security policies) with capabilities to mitigate these effects. In this section, we discuss several psychological methods to increase compliance with security policies.

Using novel polymorphic security warnings: According to Anderson et al. (2015), most people ignore security warnings on the internet due to habituation. In the field of psychology, habituation refers to a decreased response to repeated exposure to the same stimulus over time (Rankin et al., 2009). That is, we do not pay attention to objects that we repeatedly see. West (2008) also argued that most warning messages are similar to other message dialogs. Accordingly, computer system users 
TABLE 1 | Summary of individual traits founds in applicable theories and instruments.

\begin{tabular}{|c|c|c|}
\hline Individual trait & Test/theory & Instrument \\
\hline \multirow[t]{10}{*}{ Procrastination } & Big Five: & $\begin{array}{l}\text { Hunter and Schmidt Meta-Analysis } \\
\text { Procedure }\end{array}$ \\
\hline & Neuroticism & Academic Procrastination Scale \\
\hline & Dark Triad: & Adult Inventory of Procrastination \\
\hline & Machiavellianism & Aitken Procrastination Inventory \\
\hline & and Psychopathy & $\begin{array}{l}\text { Decisional Procrastination } \\
\text { Questionnaires }\end{array}$ \\
\hline & & General Procrastination Scale \\
\hline & & $\begin{array}{l}\text { Procrastination Assessment } \\
\text { Scale-Students }\end{array}$ \\
\hline & & Procrastination Log-Behaviour \\
\hline & & $\begin{array}{l}\text { Procrastination Self-Statement } \\
\text { Inventory }\end{array}$ \\
\hline & & Test Procrastination Questionnaire \\
\hline \multirow[t]{7}{*}{ Impulsiveness } & Dark Triad: & Hadlington's Examination \\
\hline & Psychopathy & Abbreviated Impulsiveness Scale \\
\hline & Narcissism & Barratt's Impulsiveness Scale \\
\hline & Big 5 Scales: & $\begin{array}{l}\text { Security Behaviours Intentions Scale } \\
\text { (SeBIS) }\end{array}$ \\
\hline & Openness & Ecological Momentary Assessment \\
\hline & Extraversion & $\begin{array}{l}\text { Dysfunctional Impulsivity subscale of } \\
\text { the Dickman }\end{array}$ \\
\hline & & Impulsivity Inventory \\
\hline \multirow[t]{6}{*}{ Future thinking } & & Internet Addiction Test \\
\hline & & Wishful Thinking Scale \\
\hline & & Automatic Thoughts Questionnaire \\
\hline & & Entrepreneurial Self-Efficacy (ESE) scale \\
\hline & & Cyber Bullying Attitude Scale \\
\hline & & Cybersecurity Attitudes Scale \\
\hline \multirow[t]{3}{*}{ Risk taking } & & Security Behaviour Intentions Scale \\
\hline & & Domain Specific Risk Taking Scale \\
\hline & & Risky Cybersecurity Behaviours Scale \\
\hline
\end{tabular}

often ignore them, as our brain is not likely to show novelty and attentional allocation response to such security warnings (Moustafa et al., 2009).

According to Wogalter (2006), the use of different polymorphic security warnings over time will help increase attention to these warnings. Along these lines, Anderson et al. (2015) found that the use of polymorphic warnings did not lead to habituation, that is, computer system users can still pay attention and respond to these security warnings. Similar findings were also found by Brustoloni and VillamarínSalomón (2007). Responding to novel and anomalous activities are aspects of situational awareness, and key for detecting phishing attempts in a cyber or network systems (D'Amico et al., 2005; Barford, 2010; Dutt et al., 2013; Knott et al., 2013; Tyworth et al., 2013; Mancuso et al., 2014; Aggarwal et al., 2018; Veksler et al., 2018). Software engineers should develop attention-capturing security warnings and not standard message dialogs, and these also should change over time in order to increase alertness and attention in computer system users. Using unique and novel security messages is important, as research have reported that these messages can increase brain activation and attentional processes (Moustafa et al., 2009, 2010; Kar et al., 2010).

In addition, other studies have compared security warning design differences between Firefox, Google and Internet Explorer browsers (Akhawe and Felt, 2013). Akhawe and Felt found that browser security warnings can be effective security mechanisms although there were a number of important variables that contribute to click through rates after warnings including warning type, number of clicks, warning appearance, certificate pinning and time spent on warnings.

Rewarding and penalizing good and bad cyber behaviour: In everyday life, we learn from negative (e.g., loss, penalties, etc.) or positive (e.g., reward) outcomes. Humans are often motivated to do certain actions to receive reward and avoid negative outcomes (Frank et al., 2007; Moustafa et al., 2008, 2013, 2015, 2017; Bodi et al., 2009; Piray et al., 2014; Myers et al., 2016). However, in the case of cyber security behaviours, the reward is that nothing bad will happen; that is, the user's computer system will not be attacked if they comply with security policies. In other words, complying with cyber security behaviours is an example of negative reinforcement in which actions (i.e., complying with cyber security policies) prevent the occurrence of a negative outcome (Sidman, 2006; May et al., 2020).

Based on these findings, the use of more concrete rewards and losses may increase compliance with security policies. For example, companies should enforce fines (kind of punishment learning) on employees who do not adhere to security policies and reward ones who do. Maqbool et al. (2020) argued that penalizing individuals should increase security behaviours. Along these lines, Baillon et al. (2019) used a phishing experiment (in which participants click on a link which then ask them to provide their passwords) to study how simulated experience with prior phishing can impact future behaviour. They found that experiencing simulated phishing (i.e., a negative outcome) increases compliance with security policies in the computer system users. It has been found that providing information about the prevalence of phishing (i.e., negative outcome can occur to people) can decrease clicking on suspicious links in phishing emails (Baillon et al., 2019). Accordingly, computer system users should be provided with simulated experience of negative outcomes that may occur due to their erroneous cyber security policies. Further, future studies should explore whether rewarding compliance with security policies will increase future pro security behaviours (Regier and Redish, 2015).

Along these lines, according to Tversky and Kahneman (1986), most people prefer a certain small reward over uncertain big reward, but people prefer uncertain loss than a certain loss (for discussion, also see for discussion, also see Herzallah et al., 2013). In other words, people generally prefer to gamble on losses. This is evident in security behaviours. Given that the reward related to security behaviours is not direct (i.e., nothing bad will happen), using a strong reward should increase adherence to security behaviours. Future research should also investigate the relationship between individual differences in response 
to rewarding and penalizing outcomes and compliance with security behaviours.

Increasing thinking about future consequence of actions: As mentioned above, some of the key features about lack of complying with cyber security policies is not thinking much about future consequences. It has been found that thinking about future consequences is related to reflective decision making and planning (Eskritt et al., 2014) and can decrease impulsive behaviours, which is related to risky behaviours on the web as we discussed above (Bromberg et al., 2015, 2017). Accordingly, using psychological methods to increase thinking about future consequences of actions can help increase reflective decision making, and thus improve cyber security behaviours (Altintas et al., 2020).

\section{CONCLUSION AND FUTURE DIRECTIONS}

Our review shows that some personality traits, such as impulsivity, risk taking, and lack of thinking about future consequences of actions, are related to a lack of compliance with cyber and network security policies. Future research should focus on developing a battery of tests to integrate personality traits and cognitive processes related to cyber and network security behaviours in one framework. This battery of tests should include cognitive processes discussed above, including impulsivity, risk taking, and thinking about future consequences of actions. Furthermore, here, we show that some psychological methods can increase pro-security behaviours, such as rewarding and penalizing security-related behaviours, using novel polymorphic security warnings, and using psychological methods to increase thinking about future consequences of actions. In addition, there are cognitive training methods, including working memory training, that help reduce impulsivity, risk taking and procrastination in the general population (Rosenbaum et al., 2017; Peckham and Johnson, 2018). Such cognitive training methods can be used to ameliorate these behavioural traits and help improve cybersecurity behaviours.

As discussed above, there are different kinds of human errors that can undermine computer and security systems, including sharing passwords, oversharing information on

\section{REFERENCES}

Aggarwal, P., Frédéric, M., Gonzalez, M. C., and Dutt, V. (2018). Understanding cyber situational awareness in a cyber security game involving recommendation. Int. J. Cyber Situat. Aware. 3, 11-38. doi: 10.22619/ijcsa.2018.100118

Akhawe, D., and Felt, A. P. (2013). "Alice in warningland: a large-scale field study of browser security warning effectiveness," in Proceedings of the 22nd USENIX Security Symposium, Washington, DC.

Alonso, C., and Romero, E. (2017). Aggressors and victims in bullying and cyberbullying: a study of personality profiles using the five-factor model. Span. J. Psychol. 20:e76.

Altintas, E., Karaca, Y., Moustafa, A. A., and El Haj, M. (2020). Effect of best possible self intervention on situational motivation and commitment social media, accessing suspicious websites, using unauthorised external media, indiscriminate clicking on links, reusing the same passwords in multiple places, using weak passwords, opening an attachment from an untrusted source, sending sensitive information via mobile networks, not physically securing personal electronic devices, and not updating software. However, most of the research conducted on human errors has been on phishing emails and sharing passwords. Future research should also investigate individual differences and contextual information (e.g., mood status, urgency at work, or multitasking) underlying other kinds of cyber security errors, such as using same or weak passwords in several websites, not connecting with virtual private networks and not encrypting data.

There are computational cognitive models applied to cybersecurity (for a review, see Veksler et al., 2018; Veksler et al., 2020). Veksler et al. (2020) argue that such cognitive models can used to predict the behaviour of attackers or computer system users. For example, Sandouka et al. (2009) used neural network models to detect social engineering attacks. The model was applied to phone conversation data, which include logs of phone calls. Each log includes date, time, where the call originated and terminated, and details of the conversation (Hoeschele, 2006). The model was used to analyse the text and detect any intrusions or social engineering attempts. Furthermore, Maqbool et al. (2020) used cognitive modeling and found that an excessive reliance on recency and frequency are related to cyber-attacks. However, future work should use computational models to better understand the relationship between cognitive processes and cybersecurity behaviours.

\section{AUTHOR CONTRIBUTIONS}

All authors listed have made a substantial, direct and intellectual contribution to the work, and approved it for publication.

\section{FUNDING}

AM acknowledges funding from Socially Engineered Payment Diversion Fraud granted by the NSW Cybersecurity Innovation Node.

in academic context. Learn. Motiv. 69:101599. doi: 10.1016/j.lmot.2019.10 1599

Anderson, B. B., Kirwan, C. B., Jenkins, J. L., and Eargle, D. (2015). "How polymorphic warnings reduce habituation in the braininsights from an fmri study," in Proceedings of the 33rd Annual ACM Conference on Human Factors in Computing Systems CHI, Crossings, Seoul.

Anderson, C. L., and Agarwal, R. (2010). Practicing safe computing: a multimethod empirical examination of home computer user security behavioral intentions. MIS Q. 34, 613-643. doi: 10.2307/257 50694

Andrade, R. O., and Yoo, S. G. (2019). Cognitive security: a comprehensive study of cognitive science in cybersecurity. J. Inf. Secur. Appl. 48:102352. doi: 10.1016/j. jisa.2019.06.008 
Bailey, P. E., Slessor, G., Rieger, M., Rendell, P. G., Moustafa, A. A., and Ruffman, T. (2015). Trust and trustworthiness in young and older adults. Psychol. Aging 30, 977-986. doi: 10.1037/a0039736

Baillon, A., de Bruin, J., Emirmahmutoglu, A., van de Veer, E., and van Dijk, B. (2019). Informing, simulating experience, or both: a field experiment on phishing risks. PLoS One 14:e0224216. doi: 10.1371/journal.pone.0224216

Barford, P. (2010). "Cyber SA: situational awareness for cyber defense," in Cyber Situational Awareness. Advances in Information Security, Vol. 46, eds P. Liu, S. Jajodia, V. Swarup, and C. Wang (Boston, MA: Springer).

Benson, V., and Mcalaney, J. (2020). Cyber Influence and Cognitive Threats. Cambridge, MA: Academic Press.

Blais, A. R., and Weber, E. U. (2006). A domain-specific risk-taking (dospert) scale for adult populations. Judgm. Decis. Mak. 1, 33-47.

Bodi, N., Keri, S., Nagy, H., Moustafa, A., Myers, C. E., Daw, N., et al. (2009). Reward-learning and the novelty-seeking personality: a between- and withinsubjects study of the effects of dopamine agonists on young Parkinson's patients. Brain 132(Pt 9), 2385-2395. doi: 10.1093/brain/awp094

Bowen, B. M., Devarajan, R., and Stolfo, S. (2014). "Measuring the human factor of cyber security," in Proceedings of the 2011 IEEE International Conference on Technologies for Homeland Security (HST), Waltham, MA.

Boyce, M. W., Duma, K. M., Hettinger, L. J., Malone, T. B., Wilson, D. P., and Lockett-Reynolds, J. (2011). "Human performance in cybersecurity: a research agenda ", in Proceedings of the Human Factors and Ergonomics Society 55th Annual Meeting.

Brase, G. L., Vasserman, E. Y., and Hsu, W. (2017). Do different mental models influence cybersecurity behavior? Evaluations via statistical reasoning performance. Front. Psychol. 8:1929. doi: 10.3389/fpsyg.2017.01929

Bravo-Lillo, C., Komanduri, S., Cranor, L., Reeder, R., Sleeper, M., Downs, J., et al. (2013). "Your attention please: designing security-decision UIs to make genuine risks harder to ignore," in Proceedings of the Symposium on Usable Privacy and Security (SOUPS), Newcastle.

Bromberg, U., Lobatcheva, M., and Peters, J. (2017). Episodic future thinking reduces temporal discounting in healthy adolescents. PLoS One 12:e188079. doi: 10.1371/journal.pone.0188079

Bromberg, U., Wiehler, A., and Peters, J. (2015). Episodic future thinking is related to impulsive decision making in healthy adolescents. Child. Dev. 86, 1458-1468. doi: $10.1111 /$ cdev. 12390

Brustoloni, J. C., and Villamarín-Salomón, R. (2007). "Improving security decisions with polymorphic and audited dialogs," in Proceedings of the SOUPS '07: 3rd Symposium on Usable Privacy and Security, New York, NY, 76-85. doi: $10.1145 / 1280680.1280691$

Cacioppo, J. T., Petty, R. E., and Feng Kao, C. (1984). The efficient assessment of need for cognition. J. Pers. Assess. 48, 306-307. doi: 10.1207/s15327752jpa 4803_13

Calic, D., Pattinson, M., and Parsons, K. (2016). "Naive and accidental behaviours that compromise information security: what the experts think," in Proceedings of the 10th International Symposium of Human Aspects of Information Security and Assurance, eds N. L. Clarke and S. M. Furnell (Frankfurt: HAISA).

Chan, M., Woon, I. M. Y., and Kankanhalli, A. (2005). Perceptions of information security at the workplace: linking information security climate to compliant behavior. J. Inf. Privacy Secur. 1, 18-41. doi: 10.1080/15536548.2005.10855772

Curtis, S., Basak, A., Carre, J., Bošansk $\imath$, B., Eern $\imath$, J., Ben-Asher, N., et al. (2021). The Dark Triad and strategic resource control in a competitive computer game. Pers. Individ. Diff. 168:110343. doi: 10.1016/j.paid.2020.110343

Curtis, S. R., Rajivan, P., Jones, D. N., and Gonzalez, C. (2018). Phishing attempts among the dark triad: patterns of attack and vulnerability. Comput. Hum. Behav. 87, 174-182. doi: 10.1016/j.chb.2018.05.037

Cybenko, G., Giani, A., and Thompson, P. (2002). Cognitive hacking: a battle for the mind. Computer 35, 50-56. doi: 10.1109/mc.2002.1023788

D'Amico, A., Whitley, K., and Tesone, D. (2005). "Achieving cyber defense situational awareness: a cognitive task analysis of information assurance analysts," in Proceedings of the Human Factors and Ergonomics Society Annual Meeting, Los Angeles, CA.

Dawson, J., and Thomson, R. (2018). The future cybersecurity workforce: going beyond technical skills for successful cyber performance. Front. Psychol. 9:744. doi: 10.3389/fpsyg.2018.00744

Diaz, A., Sherman, A. T., and Joshi, A. (2018). Phishing in an academic community: a study of user susceptibility and behavior. arXiv [Preprint] arXiv:1811.06078,
Dutt, V., Ahn, Y., and Gonzalez, C. (2013). Cyber situation awareness: modeling detection of cyber attacks with instance-based learning theory. Hum. Factors 55, 605-618. doi: 10.1177/0018720812464045

Egelman, S., and Peer, E. (2015). Scaling the security wall developing a security behavior intentions scale (SEBIS). Paper Presented at the Security Feedback \& Warnings $\mathrm{CHI}$, Seoul.

Eskritt, M., Doucette, J., and Robitaille, L. (2014). Does future-oriented thinking predict adolescent decision making? J. Genet. Psychol. 175, 163-179. doi: 10. 1080/00221325.2013.875886

Frank, M. J., Moustafa, A. A., Haughey, H. M., Curran, T., and Hutchison, K. E. (2007). Genetic triple dissociation reveals multiple roles for dopamine in reinforcement learning. Proc. Natl. Acad. Sci. U.S.A. 104, 16311-16316. doi: 10.1073/pnas.0706111104

Fraunholz, D., Anton, S. D., Lipps, C., Reti, D., Krohmer, D., Pohl, F., et al. (2019). Demystifying deception technology: a survey. arXiv [Preprint] arXiv:1804.06196,

Furnell, S., and Clarke, C. (2012). Power to the people? The evolving recognition of human aspects of security. Comput. Secur. 31, 983-988. doi: 10.1016/j.cose. 2012.08.004

Garrett, N., and Sharot, T. (2017). Optimistic update bias holds firm: three tests of robustness following Shah et al. Conscious Cogn. 50, 12-22. doi: 10.1016/j. concog.2016.10.013

Goodboy, A., and Martin, M. (2015). The personality profile of a cyberbully: examining the dark triad. Comput. Hum. Behav. 49, 1-4. doi: 10.1016/j.chb. 2015.02.052

Greenwald, S. J., Olthoff, K. G., Raskin, V., and Ruch, W. (2004). The user nonacceptance paradigm: INFOSEC's dirty little secret. Paper Presented at the New Security Paradigms Workshop, New York, NY.

Guo, K. H., Yuan, Y., Archer, N. P., and Connelly, C. E. (2011). Understanding nonmalicious security violations in the workplace: a composite behavior model. J. Manag. Inf. Syst. 28, 203-236. doi: 10.2753/mis0742-122228 0208

Gutzwiller, R. S., Fugate, S., Sawyer, B. D., and Hancock, P. A. (2015). The human factors of cyber network defense. Paper presented at the In Proceedings of the Human Factors and Ergonomics Society Annual Meeting, Los Angeles, CA.

Hadlington, L. (2017). Human factors in cybersecurity; examining the link between Internet addiction, impulsivity, attitudes towards cybersecurity, and risky cybersecurity behaviours. Heliyon 3:e00346. doi: 10.1016/j.heliyon.2017.e00346 Hadlington, L., and Murphy, K. (2018). Is media multitasking good for cybersecurity? exploring the relationship between media multitasking and everyday cognitive failures on self-reported risky cybersecurity behaviors. Cyberpsychol. Behav. Soc. Netw. 21, 168-172. doi: 10.1089/cyber.2017. 0524

Hakim, Z. M., Ebner, N. C., Oliveira, D. S., Getz, S. J., Levin, B. E., Lin, T., et al. (2020). ). The phishing email suspicion test (PEST) a lab-based task for evaluating the cognitive mechanisms of phishing detection. Behav. Res. Methods doi: 10.3758/s13428-020-01495-0 [Epub ahead of print].

Halevi, T., Lewis, J., and Memon, N. (2013). "A pilot study of cyber security and privacy related behaviour and personality traits," in Proceedings of the $W W W$ '13 Companion: 22nd International Conference on World Wide Web, Rio de Janeiro.

Hamill, R. F., and Deckro, J. M. K. (2005). Evaluating information assurance strategies. Decis. Support Syst. 39, 463-484. doi: 10.1016/j.dss.2003. 11.004

Harrison, A., Summers, J., and Mennecke, B. (2018). The effects of the dark triad on unethical behavior. J. Bus. Ethics 153, 53-77. doi: 10.1007/s10551-016-3368-3

Hazari, S., Hargrave, W., and Clenney, B. (2009). An empirical investigation of factors influencing information security behavior. J. Inf. Privacy Secur. 4, 3-20. doi: 10.1080/2333696x.2008.10855849

Henshel, D., Cains, M. G., Hoffman, B., and Kelley, T. (2015). Trust as a human factor in holistic cyber security risk assessment. Proc. Manuf. 3, 1117-1124. doi: 10.1016/j.promfg.2015.07.186

Herath, T., and Rao, H. R. (2009). Protection motivation and deterrence: a framework for security policy compliance in organisations. Eur. J. Inf. Syst. 18, 106-125. doi: 10.1057/ejis.2009.6

Herzallah, M. M., Moustafa, A. A., Natsheh, J. Y., Abdellatif, S. M., Taha, M. B. Tayem, Y. I., et al. (2013). Learning from negative feedback in patients with major depressive disorder is attenuated by SSRI antidepressants. Front. Integr. Neurosci. 7:67. doi: 10.3389/fnint.2013.00067 
Hoeschele, M. (2006). Detecting Social Engineering. CERIAS Tech Report 2006-15. Ph.D. Thesis. West Lafayette, IN: Purdue University.

Hu, Q., West, R., and Smarandescu, L. (2015). The role of self-control in information security violations: insights from a cognitive neuroscience perspective. J. Manag. Inf. Syst. 31, 6-48. doi: 10.1080/07421222.2014.1001255

Ifinedo, P. (2014). Information systems security policy compliance: an empirical study of the effects of socialisation, influence, and cognition. Inf. Manag. 51, 69-79. doi: 10.1016/j.im.2013.10.001

Jacobs, N., Goossens, L., Dehue, F., Völlink, T., and Lechner, L. (2015). Dutch cyberbullying victims' experiences, perceptions, attitudes and motivations related to (coping with) cyberbullying: focus group interviews. Societies 5, 43-64. doi: 10.3390/soc5010043

Jagatic, T. N., Johnson, N. A., Jakobsson, M., and Menczer, F. (2007). Social phishing. Commun. ACM 50, 94-100.

Jakobsson, M., and Ratkiewicz, J. (2006). "Designing ethical phishing experiments: a study of (ROT13) rOnl query features," in Proceedings of the 15th International Conference on World Wide Web Feature, Scotland

Joireman, J., Shaffer, M. J., Balliet, D., and Strathman, A. (2012). Promotion orientation explains why future-oriented people exercise and eat healthy evidence from the two-factor consideration of future consequences-14 scale. Pers. Soc. Psychol. Bull. 38, 1272-1287. doi: 10.1177/0146167212449362

Jones, A., and Colwill, C. (2008). "Dealing with the Malicious Insider," in Proceedings of the 6th Australian Information Security Management Conference, (Perth,WA: Edith Cowan University).

Kar, K., Moustafa, A. A., Myers, C. E., and Gluck, M. A. (2010). "Using an animal learning model of the hippocampus to simulate human fMRI data," in Proceedings of the 2010 IEEE 36th Annual Northeast Bioengineering Conference (NEBEC), New York, NY.

Keller, U., Strobel, A., Wollschläger, R., Greiff, S., Martin, R., Vainikainen, M., et al. (2019). A need for cognition scale for children and adolescents: structural analysis and measurement invariance. Eur. J. Psychol. Assess. 35, 137-149. doi: 10.1027/1015-5759/a000370

King, Z. M., Henshel, D. S., Flora, L., Cains, M. G., Hoffman, B., and Sample, C. (2018). Characterizing and measuring maliciousness for cybersecurity risk assessment. Front. Psychol. 9:39. doi: 10.3389/fpsyg.2018.00039

Knott, B. A., Mancuso, V. F., Bennett, K., Finomore, V., McNeese, M., and McKneely, J. A. (2013). "Human factors in cyber warfare: alternative perspectives," in Proceedings of the Human Factors and Ergonomics Society Annual Meeting, Los Angeles, CA.

Landwehr, C. (1981). Formal models of computer security. Comput. Surv. 13, 247-278. doi: $10.1145 / 356850.356852$

Lee, Y., and Kozar, K. A. (2005). Investigating factors affecting the adoption of anti-spyware systems. Commun. ACM 48, 72-77. doi: 10.1145/1076211. 1076243

Lin, Y., Durbin, J. M., and Rancer, A. S. (2016). Math anxiety, need for cognition, and learning strategies in quantitative communication research methods courses. Commun. Q. 64, 390-409. doi: 10.1080/01463373.2015.1103294

Maasberg, M., Van Slyke, C., Ellis, S., and Beebe, N. (2020). The dark triad and insider threats in cyber security. Commun. ACM 63, 64-80. doi: 10.1145/ 3408864

Mancuso, M., Christensen, J. C., Cowley, J., and Finomore, V. (2014). "Human factors in cyber warfare II: emerging perspectives," in Proceedings of the Human Factors and Ergonomics Society Annual Meeting, (Thousand Oaks, CA: SAGE Publications), 58.

Maqbool, Z., Aggarwal, P., Pammi, V. S. C., and Dutt, V. (2020). Cyber security: effects of penalizing defenders in cyber-security games via experimentation and computational modeling. Front. Psychol. 11:11. doi: 10.3389/fpsyg.2020.00011

Maurushat, A. (2010). Hackers, Fraudsters and Botnets: Tackling the Problem of Cyber Crime - The Report of the Inquiry into Cyber Crime Invited Submission to the House of Representatives Standing Committee on Communications, Parliament of Australia. Available online at: http://aph.gov. au/house/committee/coms/cybercrime/report/full_report.pdf

May, A. C., Aupperle, R. L., and Stewart, J. L. (2020). Dark times: the role of negative reinforcement in methamphetamine addiction. Front. Psychiatry 11:114. doi: 10.3389/fpsyt.2020.00114

McAlaney, J., Taylor, J., and Faily, S. (2015). The social psychology of cybersecurity. Paper presented at the 1st International Conference on Cyber Security for Sustainable Society. Coventry.
McBride, M., Carter, L., and Warkentin, M. (2012). Exploring the role of individual employee characteristics and personality on employee compliance with cybersecurity policies. RTI Int. Inst. Homel. Secur. Solut. 5:1. doi: 10.1016/j.paid.2019. 05.040

Mishra, S., and Dhillon, G. (2006). "Information systems security governance research: a behavioral perspective," in Proceedings of the 1st Annual Symposium on Information Assurance, academic track of the 9th Annual 2006 NYS Cyber Security Conference, New York, NY.

Mohebzada, J., El Zarka, A., BHojani, A. H., and Darwish, A. (2012). "Phishing in a university community: Two large scale phishing experiments," in Proceedings of the Innovations in Information Technology (IIT), International Conference, (Piscataway, NJ: IEEE), 249-254.

Moustafa, A. A., Cohen, M. X., Sherman, S. J., and Frank, M. J. (2008). A role for dopamine in temporal decision making and reward maximization in parkinsonism. J. Neurosci. 28, 12294-12304. doi: 10.1523/jneurosci.3116-08. 2008

Moustafa, A. A., Keri, S., Herzallah, M. M., Myers, C. E., and Gluck, M. A. (2010). A neural model of hippocampal-striatal interactions in associative learning and transfer generalization in various neurological and psychiatric patients. Brain Cogn. 74, 132-144. doi: 10.1016/j.bandc.2010.07.013

Moustafa, A. A., Keri, S., Polner, B., and White, C. (2017). Drift diffusion model of reward and punishment learning in rare alpha-synuclein gene carriers. J. Neurogenet. 31, 17-22. doi: 10.1080/01677063.2017.1301939

Moustafa, A. A., Keri, S., Somlai, Z., Balsdon, T., Frydecka, D., Misiak, B., et al. (2015). Drift diffusion model of reward and punishment learning in schizophrenia: modeling and experimental data. Behav. Brain Res. 291, 147154. doi: 10.1016/j.bbr.2015.05.024

Moustafa, A. A., Krishna, R., Eissa, A. M., and Hewedi, D. H. (2013). Factors underlying probabilistic and deterministic stimulus-response learning performance in medicated and unmedicated patients with Parkinson's disease. Neuropsychology 27, 498-510. doi: 10.1037/a00 32757

Moustafa, A. A., Morris, A. N., and ElHaj, M. (2018a). A review on future episodic thinking in mood and anxiety disorders. Rev. Neurosci. 30, 85-94. doi: 10.1515/ revneuro-2017-0055

Moustafa, A. A., Morris, A. N., Nandrino, J. L., Misiak, B., Szewczuk-Boguslawska, M., Frydecka, D., et al. (2018b). Not all drugs are created equal: impaired future thinking in opiate, but not alcohol, users. Exp. Brain. Res. 236, 2971-2981. doi: 10.1007/s00221-018-5355-7

Moustafa, A. A., Myers, C. E., and Gluck, M. A. (2009). A neurocomputational model of classical conditioning phenomena: a putative role for the hippocampal region in associative learning. Brain Res. 1276, 180-195. doi: 10.1016/j.brainres. 2009.04.020

Moutsiana, C., Garrett, N., Clarke, R. C., Lotto, R. B., Blakemore, S. J., and Sharot, T. (2013). Human development of the ability to learn from bad news. Proc. Natl. Acad. Sci. U.S.A. 110, 16396-16401. doi: 10.1073/pnas.130563 1110

Myers, C. E., Sheynin, J., Balsdon, T., Luzardo, A., Beck, K. D., Hogarth, L., et al. (2016). Probabilistic reward- and punishment-based learning in opioid addiction: experimental and computational data. Behav. Brain Res. 296, $240-$ 248. doi: $10.1016 /$ j.bbr.2015.09.018

Nobles, C. (2018). Botching human factors in cybersecurity in business organizations. Holistica 9, 71-88. doi: 10.2478/hjbpa-2018-0024

Parsons, K., Calic, D., Pattinson, M., Butavicius, M., McCormaca, A., and Zwaans, T. (2017). The human aspects of information security questionnaire (HAIS-Q): two further validation studies. Comput. Secur. 55, 40-51. doi: 10.1016/j.cose. 2017.01.004

Patton, J. H., Stanford, M. S., and Barratt, E. S. (1995). Factor structure of the barratt impulsiveness scale. J. Clin. Psychol. 51, 768-774. doi: 10.1002/10974679(199511)51:6<768::aid-jclp2270510607>3.0.co;2-1

Paulhus, D., and Williams, K. (2002). The dark triad of personality: narcissism, machiavellianism, and psychopathy. J. Res. Pers. 36, 556-563. doi: 10.1016/ s0092-6566(02)00505-6

Peckham, A. D., and Johnson, S. L. (2018). Cognitive control training for emotionrelated impulsivity. Behav. Res. Ther. 105, 17-26. doi: 10.1016/j.brat.2018.03. 009

Piray, P., Zeighami, Y., Bahrami, F., Eissa, A. M., Hewedi, D. H., and Moustafa, A. A. (2014). Impulse control disorders in Parkinson's disease are associated 
with dysfunction in stimulus valuation but not action valuation. J. Neurosci. 34, 7814-7824. doi: 10.1523/jneurosci.4063-13.2014

Rajivan, P., Aharonov-Majar, E., and Gonzalez, C. (2020). Update now or later? Effects of experience, cost, and risk preference on update decisions. J. Cyber Secur. 6:tyaa002.

Rajivan, P., and Gonzalez, C. (2018). Creative persuasion: a study on adversarial behaviors and strategies in phishing attacks. Front. Psychol. 9:135. doi: 10.3389/ fpsyg.2018.00135

Rankin, C. H., Abrams, T., Barry, R. J., Bhatnagar, S., Clayton, D. F., Colombo, J., et al. (2009). Habituation revisited: an updated and revised description of the behavioral characteristics of habituation. Neurobiol. Learn. Mem. 92, 135-138. doi: 10.1016/j.nlm.2008.09.012

Regier, P. S., and Redish, A. D. (2015). Contingency management and deliberative decision-making processes. Front. Psychiatry 6:76. doi: 10.3389/fpsyt.2015. 00076

Rodriguez-Enriquez, M., Bennasar-Veny, M., Leiva, A., Garaigordobil, M., and Yanez, A. M. (2019). Cybervictimization among secondary students: social networking time, personality traits and parental education. BMC Public Health 19:1499. doi: 10.1186/s12889-019-7876-9

Rosenbaum, G. M., Botdorf, M. A., Patrianakos, J. L., Steinberg, L., and Chein, J. M. (2017). Working memory training in adolescents decreases laboratory risk taking in the presence of peers. J. Cogn. Enhanc. 1, 513-525. doi: 10.1007/ s41465-017-0045-0

Sadkhan, S. B. (2019). Cognition and the future of information security. Paper presented at the 2019 International Conference on Advanced Science and Engineering (ICOASE).

Saleme, D., and Moustafa, A. A. (2020). "The multifaceted nature of risk-taking in drug addiction," in Cognitive, Clinical, and Neural Aspects of Drug Addiction, ed. A. A. Moustafa (Amsterdam: Elsevier).

Saleme, D. M., Kluwe-Schiavon, B., Soliman, A., Misiak, B., Frydecka, D., and Moustafa, A. A. (2018). Factors underlying risk taking in heroin-dependent individuals: Feedback processing and environmental contingencies. Behav. Brain Res. 350, 23-30. doi: 10.1016/j.bbr.2018. 04.052

Sandouka, H., Cullen, A., and Mann, I. (2009). Social engineering detection using neural networks. Paper Presented at the International Conference on CyberWorlds.

Sarmany-Schuller, I. (1999). Procrastination, need for cognition and sensation seeking. Stud. Psychol. 41, 73-85.

Sasse, M. A., Brostoff, S., and Weirich, D. (2004). Transforming the weakest link a human/ computer interaction approach to usable and effective security. BT Technol. J. 19, 122-131.

Schechter, S., Dhamija, R., Ozment, A., and Fischer, I. (2007). "The emperor's new security indicators," in Proceedings of the IEEE Symposium on Security and Privacy, Berkeley, CA.

Schneier, B. (2004). Secrets and Lies: Digital Security in a Networked World. Hoboken, NJ: Wiley.

Scott, S. G., and Bruce, R. A. (1995). Decision-making style: the development and assessment of a new measure. Educ. Psychol. meas. 55, 818-831. doi: 10.1177/ 0013164495055005017

Sharot, T. (2011). The optimism bias. Curr. Biol. 21, R941-R945. doi: 10.1016/j. cub.2011.10.030
Shropshire, J., Warkentin, M., Johnston, A. C., and Schmidt, M. B. (2006) Personality and IT security: an application of the five-factor model. Paper presented at the Connecting the Americas, 12th Americas Conference on Information Systems, (Acapulco: AMCIS).

Sidman, M. (2006). The distinction between positive and negative reinforcement: some additional considerations. Behav. Anal. 29, 135-139. doi: 10.1007/ bf03392126

Smith, S. W. (2003). Humans in the loop human-computer interaction and security. IEEE Comput. Soc. 1, 75-79. doi: 10.1109/msecp.2003.1203228

Stanton, J. M., Stam, J. R., Mastrangelo, P. M., and Jolton, J. A. (2005). Analysis of end user security behaviors. Comput. Secur. 24, 124-133. doi: 10.1016/j.cose. 2004.07.001

Thompson, P. (2004). Cognitive hacking and intelligence and security informatics. Proc. SPIE 5423, 142-151.

Tversky, A., and Kahneman, D. (1986). Rational choice and the framing of decisions. J. Bus. 59, 251-278.

Tyworth, M., Giacobe, N. A., Mancuso, V. F., McNeese, M. D., and Hall, D. L. (2013). A human-in-the-loop approach to understanding situation awareness in cyber defence analysis. EAI Endorsed Trans. Secur. Safe. 13:e6. doi: 10.4108/ trans.sesa.01-06.2013.e6

Veksler, V. D., Buchler, N., Hoffman, B. E., Cassenti, D. N., Sample, C., and Sugrim, S. (2018). Simulations in cyber-security: a review of cognitive modeling of network attackers, defenders, and users. Front. Psychol. 9:691. doi: 10.3389/ fpsyg.2018.00691

Veksler, V. D., Buchler, N., LaFleur, C. G., Yu, M. S., Lebiere, C., and Gonzalez, C. (2020). Cognitive models in cybersecurity: learning from expert analysts and predicting attacker behavior. Front. Psychol. 11:1049. doi: 10.3389/fpsyg.2020. 01049

Vroom, C., and von Solms, R. (2004). Towards information security behavioural compliance. Comput. Secur. 23, 191-198. doi: 10.1016/j.cose.2004.01.012

West, R. (2008). The psychology of security: why do good users make bad decisions. Commun. ACM 51, 34-40.

Whitty, M., Doodson, J., Creese, S., and Hodges, D. (2015). Individual differences in cyber security behaviors: an examination of who is sharing passwords. Cyberpsychol. Behav. Soc. Netw. 18, 3-7. doi: 10.1089/cyber.2014. 0179

Wiederhold, B. K. (2014). The role of psychology in enhancing cybersecurity. Cyberpsychol. Behav. Soc. Netw. 17, 131-132. doi: 10.1089/cyber.2014.1502

Wogalter, M. S. (2006). "Communication-human information processing (C-HIP) model," in Handbook of Warnings, ed. M. S. Wogalter (Mahwah, N.J: Erlbaum), $51-61$.

Conflict of Interest: The authors declare that the research was conducted in the absence of any commercial or financial relationships that could be construed as a potential conflict of interest.

Copyright (C) 2021 Moustafa, Bello and Maurushat. This is an open-access article distributed under the terms of the Creative Commons Attribution License (CC BY). The use, distribution or reproduction in other forums is permitted, provided the original author(s) and the copyright owner(s) are credited and that the original publication in this journal is cited, in accordance with accepted academic practice. No use, distribution or reproduction is permitted which does not comply with these terms. 